GEFAD / GUJGEF 38(2): 615-636 (2018)

\title{
Matematik Öğretmeni Adaylarının Düzlemde Dönme Dönüşümü Formüllerini Olușturma Sürecinin İncelenmesi
}

\section{Investigating Prospective Mathematics Teachers' Construction Process of Rotation Transformation Formulas on the Plane}

\author{
Hatice Kübra GÜLER ${ }^{1}$, Çiğdem ARSLAN ${ }^{2}$ \\ ${ }^{1}$ Düzce Üniversitesi Eğitim Fakültesi, Matematik ve Fen Bilimleri Eğitimi Bölümü, Matematik \\ Ĕgitimi Anabilim Dall, haticeguler@duzce.edu.tr \\ 2 Istanbul Üniversitesi Cerrahpaşa, Hasan Ali Yücel Eğitim Fakültesi, Matematik ve Fen \\ Bilimleri Eğitimi Bölümü, Matematik Eğitimi Anabilim Dal,, arslanc@istanbul.edu.tr
}

Makalenin Geliş Tarihi: 19.03.2018

Yayına Kabul Tarihi: 21.05.2018

$\ddot{O} Z$

Bu çalışmada analitik geometri dersini almış ve almakta olan ortaokul matematik ögretmeni adaylarınin düzlemde dönme dönüşümü formüllerini oluşturma süreçlerini incelemek amaçlanmıştır. Nitel olarak tasarlanmış bu çalışmada, 57 ortaokul matematik öğretmeni adayına dönme dönüşümünü kullanmadan çözebilecekleri iki soru ve bu dönüşümün formülünü oluşturmalarını gerektiren bir soru sorulmuştur. Bu sorular öğretmen adaylarına yazılı olarak verilmiş ve cevapları yazıl olarak istenmiştir. Elde edilen veriler önce betimsel olarak analiz edilmiş ve frekans değerleri belirlenmiştir. Frekans değerlerinin ortaya konmasinın ardından cevap kâğıtları nitel olarak betimsel analize tabi tutulmuştur. Yapılan analizlerin sonucunda ögretmen adaylarının tamamının birinci soruyu doğru yaptı̆̆g, ikinci soruyu sadece 45, üçüncü soruyu ise 23 öğretmen adayının doğru yaptı̆̆ görülmüştür. Birinci soru herkes tarafindan doğru yapıldı̆̆ için, ikinci ve üçüncü soru üzerine yoğunlaşılmıştır. Çalışmanın sonucunda üçüncü soruyu doğru yapan 23 ögretmen adayının 17'sinin formülleri oluşturmuş olduğu görülmüş̧ür. Diğerleri ise genellikle ya söz konusu formülleri ya da belirli açı ölçülerinde $\left(90^{\circ}-180^{\circ}-270^{\circ}\right.$ $360^{\circ}$ ) döndürme sonucunda elde edilecek noktaların hangi noktalar olduğunu doğrudan yazmıştır. Bu durum onların söz konusu formülleri ezberlediklerinin bir göstergesi olarak kabul edilebilir.

Anahtar Sözcükler: Analitik Geometri, RBC, Soyutlama, Dönme Dönüşümü

\section{ABSTRACT}

In this study, it was aimed to examine the process of forming the rotation transformation formulas in the plane of the prospective middle school mathematics teachers who have taken and are taking analytic geometry courses. In this study which was designed as qualitatively, three 
questions was asked to 57 prospective middle school mathematics teachers. There were two questions that they could solve without using the rotational transformation and a question that required them to construct this transformation. These questions were given in a written form to them and their answers were requested in writing. The obtained data were analyzed descriptively and the frequency values were determined. The first question that the recognition of the concept of rotation is enough for the solution was answered correctly by all of the prospective teachers. In the second question 45 of them answered correctly whereas in the third question this number decreased to 23. The second and third questions are focused on since the first question is done correctly by everyone. As a result of the study, it was seen that 17 of the 23 prospective teachers who made the third question correctly constructed the formulas. Others have generally found out what points are to be obtained as a result of the rotation in the formulas or the specific angle measure $\left(90^{\circ}-180^{\circ}-270^{\circ}-360^{\circ}\right)$. This situation is accepted as a sign for them to memorize the mentioned formulas.

Keywords: Analytic Geometry, RBC, Abstraction, Rotation.

\section{GíRiş}

Matematik öğretim programlarının alt öğrenme alanlarından biri olan geometri matematik derslerinde oldukça büyük bir hacme sahiptir. Öğretim programlarını etkin olarak öğretecek olan öğretmenlerin geometri bilgilerinin düzeyleri ve geliştirilmesi üzerine birçok çalışma yapılmaktadır. Geometri ve analitik geometri alanındaki bu çalışmalar incelendiğinde, daha çok dinamik geometri yazılımlarının kullanıldığı ve bu yazılımların ne denli başarılı olduğunu öne süren çalışmalar mevcuttur (Baltaci ve Baki, 2016; Karataş ve Güven, 2015; Köse ve Özdaş, 2009). Dinamik geometri yazılımlarının kullanımı, geometri konularının öğretiminde oldukça etkilidir (Mariotti, 2013). Ancak bilgisayar yazılımları, geometri öğretiminin tek aracı olarak görülmemelidir. Kaldı ki; bu tür yazılımların kullanımına ilişkin çalışmalar ülkemizde son 10 yılda artmıştır. Dolayısıyla, şu an okullarda görev yapan matematik öğretmenleri ve hâlihazırda üniversitelerde okuyan öğretmen adaylarının çoğunluğu lisede öğrenim gördükleri dönemde matematik derslerinde bu tür programları kullanma imkânı bulamamışlardır. Etkili bir öğretim ortamı oluşturulması halinde, öğrencilerin kâğıt-kalem ve pergelcetvel kullanmasıyla yapılacak öğretim de geometrik kavramların yapılandırılmasında en az dinamik geometri yazılımları kadar başarılı olabilir. 
Baltaci ve Baki (2016), öteleme ve dönme dönüşümlerinin öğrenilmesinde öğretmen adaylarının güçlük çektiğini ifade etmiş ve buradan hareketle bu kavramların öğretimi için GeoGebra kullanarak bir öğrenme ortamı tasarlamışlardır. GeoGebra kullanılarak yapılan öğretimin de öteleme, yansıma ve dönme kavramlarının yapılandırılmasına olumlu yönde katkı sağladığını belirlemişlerdir. Gürbüz ve Durmuş (2009), ortaokul matematik öğretmenlerinin dönme ile öteleme ve yansıma konusundaki yeterliklerini ayrı ayrı incelemişlerdir. Ortaokul matematik öğretmenlerinin dönüşüm geometrisi alt öğrenme alanındaki dönme konusuna ait yeterliklerinin, öteleme ve yansıma konularındaki yeterliklerden daha düşük olduğunu tespit etmişlerdir. Öğretmenler, verilen bir şekli, bir nokta etrafında ve belirtilen açıya göre döndürerek çizim yapma konusunda beklenen yeterlik düzeyinde değillerdir. Bansilal ve Naidoo'nun (2012) 12. sınıf öğrencileri ile düzlemde dönüşüm formülleri üzerine yaptıkları çalışmada, öğrencilerin bu konuda yeterli kavrama düzeyine sahip olmadıklarını belirlemişlerdir. Bazı öğrencilerin soyut olan bu kavramlara ait ön bilgilerinin mevcut olmasına rağmen, bir kısmının öğrenme sürecinde kavramlar ve işlemler arasında ilişkilendirmede güçlük çekmelerini bu durumun sebepleri arasında saymışladır.

Dönüşüm geometrisi, ortaokul matematik öğretim programı sekizinci sınıf düzeyinde yer almaktadır (MEB, 2017). Ancak programda, sadece öteleme ve yansıma kavramları bulunmaktadır. Öğretimi ortaokulda yapılan bu kavramlar, 12. sınıf geometri dersi öğretim programında analitik düzlemde temel dönüşümler konusunun temelini oluşturmaktadır. 12. sınıf geometri öğrenme alanı "trigonometrik toplam fark ve iki kat açı formülleri”, “trigonometrik denklemler” ve “analitik düzlemde temel dönüşümler” konularından oluşmaktadır (MEB, 2018). Baltaci ve Baki (2016) ile Gürbüz ve Durmuş (2009)'un çalışmalarından hareketle, ortaokul matematik öğretmenlerinin ve geleceğin öğretmenleri olan öğretmen adaylarının dönme dönüşümleri konusundaki bilgilerinin önem arz ettiği söylenebilir. Bansilal ve Naidoo 'nun (2012) da kavramsal ve işlemsel bilgileri ilişkilendirmede eksikliklerin olmasının dönme dönüşümleri ile ilgili öğrenme sürecinde zorluklar oluşturduğunu vurgulaması göz önünde bulundurulduğunda, bu konulara ilişkin önbilgileri kazandıracak olan ortaokul matematik öğretmenlerinin 
dönme dönüşüm bilgileri önem taşımaktadır. Dolayısıyla, öğretmen adaylarının lisede daha ayrıntılı görülecek olan bu kavrama ait bilgiyi ne düzeyde yapılandırdıkları araştırılması gereken bir konudur. Öğretmenler ise lisans eğitimleri süresince bu konuları analitik geometri derslerinde öğrenmektedirler ve söz konusu kavramı bu derste anlamlandırıp pekiştirmektedirler.

Matematiğin diğer alt dalları gibi, analitik geometri de kendine has bir dil ve gösterime sahiptir. Öklid geometrisinde ulaşılamayan ilişkiler, analitik geometri sayesinde kolayca tanımlanabilir, analiz edilebilir ve bir sonuca bağlanabilir (Pazarbaşı, 2015). Analitik geometrinin asıl amacı, geometri problemlerine cebirsel bir açıklama getirerek onları çözmektir (Altun, 2014:387). Bu sebeple analitik geometri ile cebirin iç içe olduğu söylenebilir. Bu çalışmada analitik geometri dersi almış ve almakta olan ortaokul matematik öğretmeni adaylarının düzlemde dönme dönüşümü formüllerini cebirsel olarak oluşturma süreçleri incelenmiştir.

Dönme dönüşümü formüllerinin oluşturulması, matematiksel bir soyutlama gerektirmektedir. Bilginin soyutlanması, Aristo ve Eflatun'dan bu yana üzerinde çalışılan bir konudur. Son yıllarda soyutlama "deneysel" ve "bilişsel" olmak üzere iki başlık altında incelenmektedir (Mitchelmore ve White, 2007). RBC adıyla anılan soyutlama teorisi de dikey matematikleştirme sürecine odaklanan bilişsel soyutlama teorilerinden biridir (White ve Mitchelmore, 2010). Bu teoride; tanıma (recognizing), kullanma (building-with) ve oluşturma (constructing) olmak üzere üç epistemik gözlenebilir davranış (Hershkowitz, Schwarz ve Dreyfus, 2001) tanımlanmıştır. Söz konusu epistemik davranışlar temel alındığında, oluşturma sürecinin analizi açık bir şekilde kolaylaşmaktadır. Bu sebeple, bu araştırmada soyutlama modellerinden RBC modeli kavramsal çatı olarak seçilmiş ve analizler bu teorik çatı altında yapılmıştır.

\section{Bilişsel Bir Soyutlama Teorisi: RBC Modeli}

Matematik, gerçek hayatın soyutlaması olarak tanımlanabilir (Altun, 2014: 13). Dreyfus (2012) öğrencilerin bilgiyi nasıl derinlemesine soyutladıklarının hem araştırmacılar hem de öğretmenler açısından önem taşıdığını belirtmektedir. Yapılandırmacı bir çerçeveden 
bakıldığında, yeni kavramların oluşturulması daha önce öğrenilmiş kavramların tam olarak yapılandırılmasına ve bu kavramlarla yeni oluşturulacak kavramlar arasındaki ilişkinin iyi bir şekilde kurulmasına bağlıdır (Dreyfus, 2012). Ancak bu yapılandırma süreçleri, zihinsel süreçler olduğundan doğrudan gözlenebilmesi mümkün olmamaktadır. Bu sebeple Hershkowitz, Schwarz ve Dreyfus (2001) matematiksel soyutlama sürecini analiz edebilmek için gözlenebilir basamaklar olan tanıma (Rrecognizing), kullanma (B-building-with) ve oluşturma (C-constructing) davranışlarını ortaya atmışlar ve teorileri bu kelimelerin İngilizce baş harfleri olan RBC olarak anılmaya başlanmıştır. Ardından Dreyfus ve Tsamir (2004), pekiştirmenin soyutlama için ne derece önemli olduğu üzerinde durmuşlar ve teoriye pekiştirmeyi de ekleyerek $\mathrm{RBC}+\mathrm{C}$ olarak kullanmaya başlamışlardır. Pekiştirme yapılandırılmış bir kavram ile ilgili ek etkinlikleri işaret etmenin yanı sıra yeni bir kavram oluşturmak için o kavramın kullanılmasını da ifade eder.

Soyutlamanın yukarıda söz edilen tanıma, kullanma ve oluşturma davranışları bağlamında analizi üzerine pek çok çalışma yapılmıştır. Kouropatov ve Dreyfus (2013), lise öğrencilerinin integral kavramını yapılandırma süreçlerini analiz etmek ve onlara bu kavramı daha iyi öğretebilmek için RBC teorisine başvururken, Kidron (2011) limit kavramında yatay asimptotların yapılandırma sürecini bu teoriye dayalı incelemiştir. Ulaş ve Yenilmez (2017), ortaokul öğrencilerinin özdeşlik oluşturma süreçlerini RBC teorisi ile analiz etmişler ve başarı düzeyleri düşük öğrencilerin özdeşlik oluşturmada güçlük yaşadıklarını belirlemişlerdir. Güler ve Arslan (2017), bir lise öğrencisi, matematik öğretmenliği alanında bir lisans ve aynı alanda bir yüksek lisans öğrencisinin Pisagor teoremini pekiştirme sürecini analiz etmede $\mathrm{RBC}+\mathrm{C}$ teorisinden faydalanmışlardır. Geometri ve analitik geometri özelinde bakıldı̆̆ında ise Sezgin Memnun ve Altun (2012), altıncı sınıf öğrencilerinin doğru denklemini oluşturma süreçlerini analiz etmek için bu teoriyi kullanmışlardır. Budiarto, Rahajuand ve Hartono (2017), ortaokul öğrencilerinin, özel dörtgenlerin arasındaki ilişkileri oluşturmalarında RBC teorisinden faydalanmışlar ve bu teori aracılığıyla dörtgenlerin arasındaki benzerlik ve farklılıkları nasıl yapılandırdıklarını analiz etmişlerdir. Nurhasanah, 
Kusumah, Sabandar ve Suryadi (2017), matematik öğretmen adaylarının kartezyen koordinat sisteminde paralel koordinatlar oluşturma süreçlerini RBC teorisi bağlamında incelemiş̧lerdir. Çalışmanın sonucunda soyutlamanın, öğrencilerin grup içi tartışmalar yaparak bilgilerini birbirleriyle paylaştıkları esnada oluştuğu belirlenmiştir.

Yukarıda bahsedilen çalışmalardan da görüldüğü gibi, $\mathrm{RBC}+\mathrm{C}$ teorisi ortaokuldan lisansüstüne kadar matematiksel yapıların oluşturulma ve pekiștirilme süreçlerini incelemede kullanılabilmektedir. Aynı zamanda geometrik kavramların oluşturulma süreçlerinin incelenmesine de imkân sağlamaktadır. Bu bilgiler ışığında, bu çalışmada lisans düzeyindeki öğrencilerin analitik geometri ile ilgili bir yapı olan dönme kavramının oluşturulma sürecini incelemede RBC modeli kullanılmıştır.

\section{YÖNTEM}

$\mathrm{Bu}$ araştırma, ortaokul matematik öğretmeni adaylarının dönüşüm formüllerini oluşturma süreçlerini inceleyen nitel bir çalışmadır. Nitel çalışmaların tek bir tanımını yapmak oldukça güçtür. Nitel araştırma bir şemsiye olarak kabul edilebilir (Yıldırım ve Şimşek, 2008). Bu çalışma nitel araştırma kavramlarından biri olan betimsel araştırma olarak nitelendirilebilir.

\section{Çalışma Grubu}

Çalışma grubu, amaçlı örnekleme yöntemi ile belirlenmiştir. Araştırmaya analitik geometri dersini almış veya almakta olan 57 öğretmen adayı katılmıştır. Bu öğretmen adaylarının 33’ü üçüncü, 24'ü ikinci sınıf öğrencisidir.

\section{Verilerin Toplanması ve Analizi}

Veriler, araştırmacılar tarafından hazırlanan bir çalışma kâğıdı aracılığı ile 2016-2017 bahar yarıyılında toplanmıştır. Çalışma kâğıdı hazırlanmasının ardından analitik geometri dersine giren bir akademisyenden de görüş alınarak veri toplama aracına son hali verilmiştir. Çalışma kâğıdında düzlemde dönme dönüşümü ile ilgili üç soru bulunmaktadır. Öğrencilere yöneltilen bu üç sorudan sonuncusu, üçüncü sınıflara 
çizimle desteklenerek yöneltilirken; ikinci sınıflara metin olarak verilmiştir. Burada amaç, öğretmen adaylarının çizimi kendisinin yapması ile çizimin hazır olarak verilmesinin dönüşüm formüllerini yapılandırmada bir farklılık yaratıp yaratmadığını görmektir. Sorular RBC soyutlama teorisi açısından analiz edilebilecek şekilde tasarlanmıştır. Birinci soru öğrencilerin sadece döndürme kavramını tanıma (Rrecognizing) davranışını sergilemelerini gerektirmektedir. İkinci soru tanımaya ek olarak bilme (B-building with) davranışının da sergilenmesini gerektirmektedir. Öğrenciler döndürme işleminde eş olan açıları belirleyebilmeli ve buna göre çözüm yapmalıdırlar. Son soru ise dönüşüm formülünü oluşturmaya (C-constructing) hizmet etmektedir. Bu araştırmada öğretmen adaylarına yöneltilen sorular aşağıdaki gibidir:

\section{Birinci Soru:}

A $(1,3)$ noktasının pozitif yönde $180^{\circ}$ döndürülmesi ile elde edilen $\mathrm{B}$ noktasının koordinatları nedir?

İkinci Soru:

A $(5,-2)$ noktasının pozitif yönde $90^{\circ}$ döndürülmesi ile elde edilen $\mathrm{B}$ noktasının koordinatları nedir?

Ikinci Stnıflara Sorulan Üçüncü Soru:

Herhangi bir $\mathrm{A}(\mathrm{x}, \mathrm{y})$ noktasının pozitif yönde $\alpha$ derece döndürülmesi sonucu oluşan $\mathrm{B}$ (a, b) noktasını A noktası ve $\alpha$ cinsinden nasıl ifade edersiniz?

Üçüncü Sinıflara Sorulan Üçüncü Soru: 


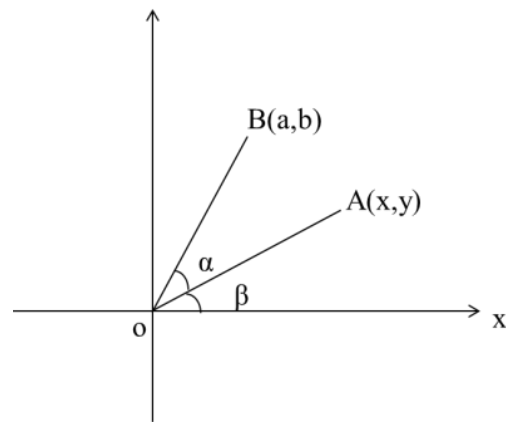

B (a, b) noktasi; A (x, y)

noktasının pozitif yönde $\alpha$ derece döndürülmesi ile elde edilen noktadır. B noktasının bileşenlerini; A noktası ve $\alpha$ cinsinden nasıl ifade edersiniz?

Öğretmen adaylarından birinci ve ikinci soruların çözümünde çizim yapması ve bu şekilde istenen noktaları tespit etmesi beklenmektedir. Üçüncü soruda ise trigonometrik toplam fark formüllerini kullanarak B noktasını ifade etmeleri beklenmektedir. Bu soru için öğretmen adaylarının yapması beklenen işlemler aşağıdaki gibidir:

$$
\begin{gathered}
\sin \beta=\frac{y}{\sqrt{x^{2}+y^{2}}}, \cos \beta=\frac{x}{\sqrt{x^{2}+y^{2}}}, \\
\sin (\alpha+\beta)=\frac{b}{\sqrt{x^{2}+y^{2}}}, \cos (\alpha+\beta)=\frac{a}{\sqrt{x^{2}+y^{2}}} \\
\sin (\alpha+\beta)=\sin \alpha \cdot \cos \beta+\sin \beta \cdot \cos \alpha \quad \mathrm{ve} \\
\cos (\alpha+\beta)=\cos \alpha \cdot \cos \beta-\sin \beta \cdot \sin \alpha \\
a=\mathrm{x} \cdot \cos \alpha-y \cdot \sin \alpha \\
b=\mathrm{x} \cdot \sin \alpha+y \cdot \cos \alpha
\end{gathered}
$$

Öncelikle soruların ne kadarının doğru yapıldığına ilişkin betimsel istatistik yapılmış ve frekans tabloları oluşturulmuştur. Ardından üçüncü soruda dönüşüm formüllerinin yapılandırılmasına ilişkin veriler, RBC teorisi ışığında iki araştırmacı tarafından ayrı ayrı betimsel analiz metoduyla analiz edilmiştir. Betimsel analiz metodunda toplanan veriler daha önceden belirlenmiş temalar altında sunulur (Yıldırım ve Şimşek, 2008).

Bu doğrultuda araştırmacılar tarafından yapılan analiz sonuçları karşılaş̧ırılmış ve ortak bir karara varılmasının ardından öğrencilerin cevapları ile de desteklenerek elde edilen bulgular yorumlanmıştır. Sorulara verilen cevaplar doğru, kısmen doğru ve yanlış olarak kodlanmıştır. Bu kodlamada birinci ve ikinci soru için "çizim var ve sonuç doğru", "çizim yok ve sonuç doğru", "formül kullanılarak yapılmış ve sonuç doğru" 
olarak yapılan kodlamalar, doğru cevap olarak kabul edilmiştir. "Çizim var ancak sonuç yanlış, "çizim yok ve sonuç yanlış", "formül kullanılmış ve sonuç yanlış" ve "boş" olarak yapılan kodlamalar, yanlış cevap olarak kabul edilmiştir. Üçüncü soruya gelindiğinde ise bir ve ikinci sorudaki kodlamalara ek olarak "deneme yanılma ile doğru" kodu alan soru doğru kabul edilmiştir. "Bilinen ölçüleri yazma" ve "sadece çizim var" kodlamaları kısmen doğru olarak kabul edilmiştir.

\section{BULGULAR}

Bu bölümde öncelikle, öğretmen adaylarının her bir soruya verdikleri cevapların frekans tablosu oluşturulmuş ve bu tablolar betimsel analiz sonuçları başlığı altında sunulmuştur. Ardından RBC çerçevesinde üçüncü sorunun analizi yapılarak bu analiz tablolar halinde verilmiştir. Yapılan analizler sonucunda, üçüncü soruyu, üçüncü sınıflardan 10 öğretmen adayının, ikinci sınıflardan ise 11 öğretmen adayının yanlış yanıtlamış olduğu görülmüştür. Kâğıtlar incelendiğinde, üçüncü sorunun farklı şekilde yöneltilmesinin öğretmen adaylarının soruyu doğru yanıtlamasında önemli derecede bir farklılık yaratmadı̆̆ çizimle verilmiş olması arasındaki fark göz önünde bulundurulmadan analizler yapılmıştır

\section{Betimsel Analizden Elde Edilen Bulgular}

Öğretmen adaylarının üç soruya verdikleri cevapların analizi Tablo 1'de görülmektedir. Çözümü için dönme kavramının tanınmasının yeterli olduğu birinci soruyu, öğretmen adaylarının tamamı doğru cevaplandırmıştır. Bu durum, öğretmen adaylarının ortaokul yıllarından beri bu konuları görmesinden ve soru sadece tanıma davranışını gerektirmesinden ötürü, beklenen bir durumdur. İkinci soruyu ise 45 kişi doğru cevaplandırırken üçüncü soruda bu sayı 23'e düşmüştür.

Tablo 1. Sorulara Verilen Cevapların Frekansları 


\begin{tabular}{ccccc}
\hline & Doğru & Kismen Doğru & Yanlış & Toplam \\
\hline Soru 1 & 57 & - & - & 57 \\
Soru 2 & 45 & - & 12 & 57 \\
Soru 3 & 23 & 13 & 21 & 57 \\
\hline
\end{tabular}

Tablo 1'den elde edilen bilgilerden hareketle ikinci ve üçüncü soru için daha ayrıntılı bir inceleme yapılmış ve Tablo 2'de sunulmuştur. Tablo 2 incelendiğinde, ikinci soruyu doğru yapan 45 öğretmen adayının 20'sinin üçüncü soruyu da doğru yaptığı görülmektedir. Bu tablodaki daha dikkat çekici bir sonuç ise üçüncü soruya nazaran daha basit düzeyde bir soru olan ikinci soruyu yanlış yapan 12 öğretmen adayının 3’ünün oluşturma basamağına hitap eden üçüncü soruyu doğru yapmasıdır.

Tablo 2. İki ve Üçüncü Soruya Verilen Cevapların Frekansları

\begin{tabular}{cc}
\hline Soru 2 & Soru 3 \\
\hline Doğru (45) & Doğru (20) \\
Kismen Doğru (18) \\
Yanlış (7) \\
\hline Yanlış (12) & Doğru (3) \\
& Kısmen Doğru (3) \\
& Yanlış (6) \\
\hline
\end{tabular}

Bu öğretmen adaylarının kâğıtları nitel olarak incelendiğinde ise üçüncü soruyu doğru yapan iki öğretmen adayının ikinci soruda noktayı istenen açı kadar döndürmek yerine noktanın x eksenine göre simetrisini aldıkları, üçüncü soruyu oluşturmada ise toplamfark formüllerini kullanmış ve istenen formülü oluşturmuş oldukları görülmüştür. $\mathrm{Bu}$ öğretmen adaylarından birinin (Ö7) ikinci ve üçüncü soruya verdiği cevap Şekil 1'de görülmektedir. 

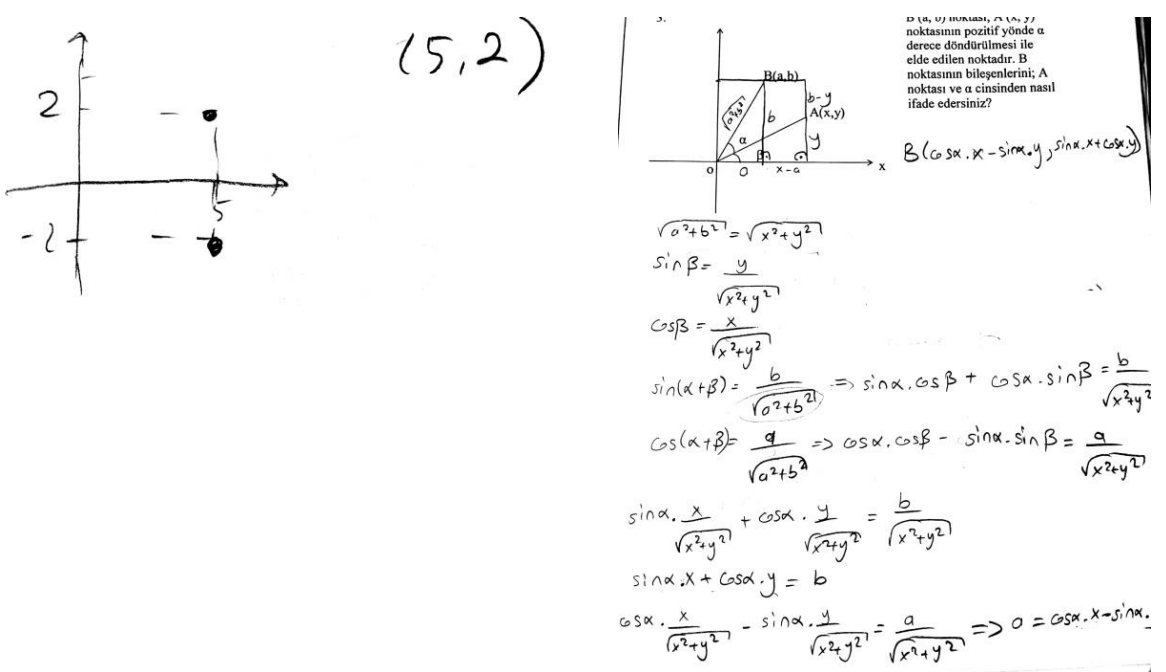

Şekil 1. Ö7'nin ikinci ve üçüncü soruya verdiği cevap

Diğer öğretmen adayı ise ikinci soruyu çözerken döndürülmek istenen noktayı koordinat düzleminde yanlış yerleştirmiş ve bu sebeple döndürme sonucunda elde edilen noktayı yanlış bulmuştur. Üçüncü soruda ise istenen dönüşümü herhangi bir işlem yapmadan doğrudan yazmıştır. $\mathrm{Bu}$ durum formülü ezberlediğinin bir göstergesi olarak kabul edilebilir ve ezberlenerek doğru yazılan bir bilginin yapılandırıldığını söylemek güçtür.

Öğretmen adaylarının üçüncü soruyu yapmada yaşadıkları güçlükleri ve dönme dönüşümü formüllerini oluşturma sürecindeki eksikliklerini ortaya koymak amacıyla RBC soyutlama teorisi ışığında yapılan analiz sonuçları aşağıda verilmiş̧tir.

\section{Üçüncü Sorunun RBC Açısından Analizi}

Öğretmen adaylarının kâğıtları $\mathrm{RBC}+\mathrm{C}$ teorisi çerçevesinde incelendiğinde, üçüncü soruyu doğru yapan 23 öğretmen adayının 17'sinin (Ö1, Ö6, Ö7, Ö8, Ö10, Ö16, Ö17, Ö24, Ö30, Ö31, Ö32, Ö35, Ö39, Ö53, Ö57, Ö59, Ö65) dönüşüm formüllerini yapılandırmış olduğu görülmüştür. Altı öğretmen adayının ise ya söz konusu formülleri ya da belirli açı ölçülerinde $\left(90^{\circ}-180^{\circ}-270^{\circ}-360^{\circ}\right)$ döndürme sonucunda elde edilecek 
noktaların hangi noktalar olduğunu ezberledikleri tespit edilmiştir. Öğretmen adaylarının ikinci soruya verdikleri cevaplar temel alınarak üçüncü soruya verdikleri cevapları analiz edilmiş ve aşağıda ayrıntılı olarak sunulmuştur. Öncelikle ikinci soruyu doğru yapmasına rağmen nasıl yaptı̆̆ını açıklamayan, ardından ikinci soruyu açıklamasını da yaparak doğru yapan öğretmen adaylarının üçüncü soruya verdikleri cevapların analizi yapılmışır. Daha sonra sırasıyla ikinci soruyu belli açıları temel alarak $\left(90^{\circ}-180^{\circ}-270^{\circ}-360^{\circ}\right)$ doğru yapan, ikinci soruyu doğrudan formül kullanarak yapan ve ikinci soruyu tamamen yanlış yapan öğretmen adaylarının üçüncü soruya verdikleri cevaplar analiz edilmiştir.

İkinci Soruyu Doğru Yapmasına Rağmen Açıllama Yapmayan Öğretmen Adaylarının Üçüncü Soruya Verdikleri Cevaplar

İkinci soruyu doğru yapan 45 öğretmen adayının yedisi, çizimle ya da sözel olarak hiçbir açıklama yapmamışlardır. Sadece döndürme sonucunda oluşacak noktayı analitik düzlemde işaretlemişler veya doğrudan hangi noktanın oluşacağını yazmışlardır. Bu öğretmen adaylarının üçüncü soruyu da yanlış yaptıkları görülmüştür ve cevaplarının analizi Tablo 3'te verilmiştir. Bu tablodan, ikinci soruyu doğru yapmasına rağmen nasıl yaptığını açıklamayan öğretmen adaylarının üçüncü soruda dönme dönüşümü formüllerini yapılandıramadıkları görülmektedir.

Tablo 3. İkinci Soruyu Doğru Yapmasına Rağmen Açılama Yapmayan Öğretmen Adaylarının Üçüncü Soruya Verdikleri Cevaplar

Soru 3'e verilen cevaplar

Boş (Ö3, Ö15)

İlgili açıları birbiri cinsinden yazmaya çalışmış (Ö14)

Sinüs ve kosinüs için toplam fark yerine tanjant için toplam formülünü kullanmış (Ö21)

Toplam-fark formüllerini kullanmış ancak bu formülleri yanlış yazmış (Ö26)

Doğrudan formül yazmış (Ö28)

Kartezyen koordinatları kutupsal koordinat olarak ifade etmiş (Ö37) 
Ikkinci Soruyu Açıklaması İle Beraber Doğru Yapan Öğretmen Adaylarının Üçüncü Soruya Verdikleri Cevaplar

İkinci soruyu doğru yapan 45 öğretmen adayının 19'u cevap ile ilgili sözel olarak ya da çizimle açıklamada bulunmuştur. Bu öğretmen adaylarının sadece 7'sinin (Ö1, Ö16, Ö17, Ö30, Ö31, Ö32, Ö39) dönme dönüşümü formülünü yapılandırdıkları belirlenmiştir ve cevapları Tablo 4’te özetlenmiştir.

Tablo 4'te, döndürme yapabilmelerine ve yaptıklarını açıklayabilmelerine rağmen dönme dönüşümü formüllerini oluşturamayan öğretmen adaylarının formülleri doğrudan yazma eğilimi gösterdikleri, sinüs ve kosinüs yerine tanjant toplam fark formülünü kullandıkları görülmektedir. 
Tablo 4. İkinci Soruyu Açıklaması İle Beraber Doğru Yapan Öğretmen Adaylarının Üçüncü Soruya Verdikleri Cevaplar

\section{Soru 2'ye yapılan açıklama \\ Soru 3'e verilen cevap}

\begin{tabular}{|c|c|}
\hline $\begin{array}{l}\text { Döndürme yaptığını çizim ile } \\
\text { göstermiş }\end{array}$ & $\begin{array}{l}\text { Trigonometrik toplam fark formüllerini doğru bir } \\
\text { şekilde kullanarak doğru sonuca ulaşmış, dönme } \\
\text { dönüşümü formüllerini yä } \\
\text { (Ö1,Ö16,Ö17,Ö30, Ö31,Ö32, Ö39) } \\
\text { Direk formül yazmaya çalışmış ancak yanlış } \\
\text { yazmış, açıları doğru taşıyamamış (Ö5) }\end{array}$ \\
\hline $\begin{array}{l}\text { Hem çizim hem de sözel olarak } \\
\text { açıklama ve döndürme kavramına } \\
\text { atıf }\end{array}$ & $\begin{array}{l}\text { Eş olan doğru parçalarını tanımlayamamış } \\
\text { (IOAI=IOBI), Formülleri oluşturmak için kosinüs } \\
\text { teoremini kullanmış (Ö4) }\end{array}$ \\
\hline $\begin{array}{l}\text { Çizim ile açıklama (benzerlikten } \\
\text { yararlanarak eş açıları belirlemiş) }\end{array}$ & $\begin{array}{l}\text { Sonucu yazamamasına rağmen trigonometrik } \\
\text { toplam fark formüllerini kullanmış ve formülleri } \\
\text { oluşturma konusunda yol almış (Ö9) }\end{array}$ \\
\hline \multirow[t]{2}{*}{$\begin{array}{l}\text { Döndürme yaptığını } \\
\text { göstermiş }\end{array}$} & $\begin{array}{l}\text { Sinüs ve kosinüs için toplam fark yerine tanjant } \\
\text { için toplam formülünü kullanmış (Ö29) } \\
\text { Doğrudan formül yazmış (Ö33,Ö49, Ö51,Ö52, } \\
\text { Ö63) } \\
\text { Boş (Ö50) }\end{array}$ \\
\hline & $\begin{array}{l}\text { Kartezyen koordinatları kutupsal koordinat olarak } \\
\text { ifade etmiş (Ö55) } \\
\text { Formülleri oluşturmak için kosinüs teoremini } \\
\text { kullanmış (Ö64) }\end{array}$ \\
\hline
\end{tabular}

İkinci Soruyu Belli Açıları Baz Alarak Doğru Yapan Öğretmen Adaylarının Üçüncü

Soruya Verdikleri Cevaplar

İkinci soruda belli açıları $\left(90^{\circ}-180^{\circ}-270^{\circ}-360^{\circ}\right)$ ezberleyerek doğru sonuca ulaşan 16 öğretmen adayı vardır. Bu öğretmen adaylarının sadece 6’sının (Ö57, Ö6, Ö10, Ö24, Ö59, Ö65) dönme dönüşümü formüllerini yapılandırdıkları belirlenmiştir ve cevapları Tablo 5'te özetlenmiştir.

Tablo 5. İkinci Soruyu Belli Açıları Baz Alarak Doğru Yapan Öğretmen Adaylarının Üçüncü Soruya Verdikleri Cevaplar

Soru 3'e verilen cevaplar

Trigonometrik toplam fark formüllerini doğru bir şekilde kullanarak doğru sonuca ulaşmış dönme dönüşümü formüllerini yapılandırmış (Ö6, Ö10, Ö24, Ö57, Ö59, Ö65) 
Kartezyen koordinatları kutupsal koordinat olarak ifade etmiş (Ö12, Ö19, Ö34)

Doğrudan formül yazmış ve belli açıları kullanarak formülün doğruluğunu test etmiş (Ö18)

Doğrudan formül yazmış (Ö20, Ö25, Ö36, Ö58)

Boş (Ö45)

Belli açıları yazmış (Ö54)

Tablo 5'te görüldüğü gibi, dönme dönüşümü formüllerini oluşturamayan öğretmen adayları genel olarak formülleri doğrudan yazma eğilimi göstermişlerdir.

İkinci Soruyu Doğrudan Formül Kullanarak Yapan Öğretmen Adaylarının Üçüncü Soruya Verdikleri Cevaplar

İkinci sorunun çözümü için dört öğretmen adayı, düzlemde dönme dönüşümü formüllerini kullanmışlardır. Ancak bu öğretmen adaylarından üçü, ikinci soru için doğru cevaba ulaşırken sadece biri (Ö35) ikinci soruya yanlış cevap vermiştir. Buna rağmen iki öğretmen adayının dönme dönüşümünü yapılandırdıkları belirlenmiştir ve cevapları Tablo 6'da özetlenmiştir.

Tablo 6. İkinci Soruyu Doğrudan Formül Kullanarak Yapan Öğretmen Adaylarının Üçüncü Soruya Verdikleri Cevaplar

\section{Soru 3'e verilen cevaplar}

Trigonometrik toplam fark formüllerini doğru bir şekilde kullanarak doğru sonuca ulaşmış, dönme dönüşümü formüllerini yapılandırmış (Ö35, Ö53)

Doğrudan formül yazmış (Ö42, Ö56)

İkinci Soruyu Tamamen Yanlış Yapan Öğretmen Adaylarının Üçüncü Soruya Verdikleri Cevaplar

11 öğretmen adayından 10’u ikinci soruda noktayı döndürmek yerine, noktanın $\mathrm{x}$ eksenine göre simetrisini alarak yanlış yapmıştır. Döndürme yapan Ö48 pozitif yönde değil, negatif yönde döndürmüştür ve bu yüzden yanlış nokta bulmuştur. Bu öğretmen adaylarından sadece ikisinin (Ö7 ve Ö8) dönme dönüşümünü yapılandırdıkları belirlenmiştir ve cevapları Tablo 7'de özetlenmiştir. 
Tablo 7. İkinci Soruyu Tamamen Yanlış Yapan Öğretmen Adaylarının Üçüncü Soruya Verdikleri Cevaplar

\section{Soru 3'e verilen cevaplar}

Trigonometrik toplam fark formüllerini doğru bir şekilde kullanarak doğru sonuca ulaşmış, dönme dönüşümü formüllerini yapılandırmış (Ö7, Ö8)

Trigonometrik toplam fark formüllerini yazmış ancak sonuca ulaşamamış (Ö22, Ö40)

Trigonometrik oranları kullanmış ancak eş olmayan açıları eş kabul etmiş ve formülleri oluşturamamış (Ö23)

Doğrudan formül yazmaya çalışmış ancak yanlış yazmış (Ö27)

Doğrudan formül yazmış (Ö38)

Kartezyen koordinatları kutupsal koordinat olarak ifade etmiş (Ö48)

Boş (Ö60, Ö61, Ö62)

\section{TARTIŞMA ve SONUÇ}

$\mathrm{Bu}$ çalışmada analitik geometri dersi almış ve almakta olan ortaokul matematik öğretmeni adaylarının düzlemde dönme dönüşümü formüllerini oluşturma süreçlerini incelemek amaçlanmıştır. Kouropatov ve Dreyfus (2013) teorik soyutlama sürecinde, yapılandırılmak istenen kavram ile bu kavramın yapılandırılması için kullanılacak diğer kavramlar arasında dikey bir ilişki olduğunu belirtmektedirler. Bu sebeple, analizlerine diğer kavramları da dâhil etmişlerdir. Onların bu düşüncesinden hareketle, bu çalışmada sorulan ilk iki soru bu kapsamda değerlendirildiğinde, öğretmen adaylarının yapılandırma için gerekli kavramsal alt yapıya sahip oldukları söylenebilir.

RBC açısından bakıldığında; öğretmen adaylarının tamamının birinci soruyu doğru yapmaları, dönme kavramını yapısal olarak tanıdıklarını göstermektedir. Tüm öğretmen adayları, teorik olarak bu bilgiye sahiptirler. Ancak ikinci soruyu 45 kişinin doğru, 12 kişinin yanlış yaptığı göz önünde bulundurulduğunda, öğretmen adaylarının tanıdıkları bir kavramı kullanma hususunda eksiklikleri olduğu görülmektedir. Düzlemde dönme dönüşümü formülünü oluşturabilmek için önkoşul, teorik olarak dönme kavramının ne olduğunu bilmek ve kullanabilmektir. Öğretmen adaylarının istenen dönüşüm 
formülünü oluşturmak için bir girişimde bulunmalarına rağmen başarılı olamamaları, önceki bilgileri tam olarak yapılandıramamış olmalarından kaynaklanabilir.

Kidron (2011) da, kavramın imajı ile tanımı arasındaki ilişkiyi teorik soyutlama süreci doğrultusunda mevcut çalışmada olduğu gibi üç soru ile analiz etmiştir ve sonuçta her soruda bir adım ileri gidildiğini ve öğrencinin sürece daha çok adapte olduğunu belirlemiştir. Benzer şekilde bu çalışmada da öğrenciler ilk iki soruda konuya adapte olmuş ve üçüncü soruda neyi yapılandırmaları beklendiğini fark etmişlerdir.

Dreyfus (2012), RBC modelinin derin matematik bilgisini ortaya çıkartmaya yardımcı olacağını ifade etmektedir. $\mathrm{Bu}$ modeldeki epistemik davranışlara göre analiz yapıldığında, öğretmen adaylarının matematik bilgilerinde yeterli düzeyde derinlik olmadığı görülmektedir. Tanıma ve bilme davranışlarında başarılı olmalarına rağmen, oluşturma davranışında benzer performansı gösterememişlerdir. Formülleri doğrudan yazmaları onların dönme dönüşümü formüllerini yapılandırmaktan ziyade, ezberleme eğiliminde olduklarını göstermektedir.

Dönme dönüşümü formülünü oluşturabilen öğretmen adaylarının dönme kavramını hem tanıdıkları hem de kullanabildikleri söylenebilir. Sadece iki kişi kullanma konusunda güçlük yaşamasına rağmen, bu formülü yapılandırabilmiştir. Bulgularda da bahsedildiği gibi, öğretmen adaylarının kullanmada yaşadıkları güçlük, simetri kavramı ile dönme kavramını karıştırmalarından kaynaklanmaktadır.

Kâğıtların incelenmesi ile ortaya çıkan diğer bir sonuç, ne yaptığını açıklayabilen öğretmen adaylarının dönme dönüşümü formüllerini yapılandırmada daha başarılı olduklarıdır. Bu durum, Nurhasanah ve diğerlerinin (2017) çalışmasından çıkan “öğrencilerin oluşturdukları bilgileri birbirleriyle paylaşmaları halinde yapılandırmanın daha iyi gerçekleştiği” sonucunu desteklemektedir. Bilgiyi yapılandıran öğretmen adayları, o kavramla ilgili bir sorunun çözümünde gerekli açıklamaları yapabilmektedirler. Ulaş ve Yenilmez de (2017) çalışmalarında, matematik başarısına göre düşük, orta ve yüksek olarak ayırdıkları gruplardan yüksek başarıya sahip öğrencilerin özdeşlik kavramını daha iyi içselleştirdiğini ve oluşturduğunu 
belirtmektedirler. Bu bağlamda "ne yaptığını açıklayabilme”nin öğrenmenin bir göstergesi olduğu göz önünde bulundurulduğunda, mevcut çalışmada ne yaptığını açıklayabilen öğretmen adaylarının dönme dönüşümü formüllerini oluşturmada daha başarılı olması beklenen bir durumdur.

Öğretmen adaylarının sorunun sadece doğru cevabını yazmaları bilgiyi yapılandırdıklarının bir göstergesi değildir. Öğretmen adaylarından istenen formülü oluşturmalarıdır. Doğrudan formülü yazan öğretmen adaylarının ikinci soruda ne yaptığını açıklayamamaları ya da ikinci soruyu doğru yapsalar bile bunu genellemekten ziyade belli açı ölçülerinin sonuçlarını yazmaları, bilgiyi yapılandırmada eksiklerinin olduğu sonucunu destekler niteliktedir. Sadece beş öğretmen adayı ikinci soruda ne yaptığını açıklamakla beraber, üçüncü soruda doğrudan formül yazma eğilimi göstermiştir. Toluk-Uçar’ın (2011) öğretmen adaylarının genelde kural ve yöntemlerin ne olduğunu ve nasıl uygulanacağını bilmesine rağmen, verilen durumların altında yatan anlama uygun matematiksel açıklamalar oluşturamadıklarını belirtmiştir. Benzer şekilde, Pazarbaşı ve Es’in (2015) ilköğretim matematik öğretmen adaylarının analitik geometri alan dilini kullanma becerileri ve tutumlarını incelediği çalışmalarında da alan dilini öğrenirken klasik ve geleneksel yöntemleri kullanıp ezberleme yolunu seçtikleri ortaya koyulmuştur. Daha önce yapılmış bu çalışmaların sonuçlarına paralel olarak, bu çalışmanın sonuçları da, öğretmen adaylarının düzlemde dönme dönüşümü formülünü kullanma konusunda eksikliklerinin olduğunu, ezbere yöneldiklerini ve söz konusu formülleri yapılandıramadıklarını göstermektedir. 


\section{KAYNAKLAR}

Altun, M. (2014). Ortaokullarda (5, 6, 7 ve 8. sınıflarda) matematik öğretimi. 10. Bask1. Bursa: Alfa Aktüel.

Baltaci, S., ve Baki, A. (2016). Dinamik matematik yazılımının öteleme ve dönme dönüşümlerinin öğretiminde kullanılmasının bağlamsal öğrenme boyutundan incelenmesi. Ondokuz Mayıs Üniversitesi Eğitim Fakültesi Dergisi, 35(1), 119 139.

Bansilal, S., and Naidooo, J. (2012). Learners engaging with transformation geometry. South African Journal of Education, 32(1), 26-39.

Budiarto, M. T., Rahajuand, E. B., and Hartono, S. (2017). Students abstraction in re cognizing, building with and constructing a quadrilateral. Educational Research and Reviews, 12(7), 394-402.

Dreyfus, T. (2012). Constructing abstract mathematical knowledge in context. The paper was presented at 12th International Congress on Mathematical Education, Seoul, Korea.

Dreyfus, T., and Tsamir, P. (2004). Ben's consolidation of knowledge structures about infinite sets. Journal of Mathematical Behavior, 23, 271-300.

Güler, H. K., ve Arslan, Ç. (2017). Consolidation of similarity knowledge via Pythagorean Theorem: a Turkish case study. Acta Didactica Napocensia, 10(2), 67-79.

Gürbüz, K., ve Durmuş, S. (2009). İlköğretim matematik öğretmenlerinin dönüşüm geometrisi, geometrik cisimler, örüntü ve süslemeler alt öğrenme alanındaki yeterlikleri. Abant İzzet Baysal Üniversitesi Ĕ̈itim Fakültesi Dergisi. 9(1), 1 21.

Hershkowitz, R., Schwarz, B. B., and Dreyfus, T. (2001). Abstraction in context: Epistemic actions. Journal of Research in Mathematics Education, 32(2), 195 222.

Karataş, İ., ve Güven, B. (2015). Dinamik geometri yazılımı Cabri'nin matematik eğitiminde kullanımı: Pisagor bağıntısı ve çokgenlerin dış açıları. Gazi Eğitim Bilimleri Dergisi, 1(1), 15-28.

Kidron, I. (2011). Constructing knowledge about the notion of limit in the definition of the horizontal asymptote. International Journal of Science and Mathematics Education, 9, 1261-1279.

Kouropatov, A. and Dreyfus, T. (2013). Constructing the integral concept on the basis of the idea of accumulation: suggestion for a high school curriculum. International Journal of Mathematical Education in Science and Technology, 44(5), 641-651. 
Köse, N. Y. ve Özdaş, A. (2009). İlköğretim 5. sınıf öğrencileri geometrik şekillerdeki simetri doğrularını Cabri geometri yazılımı yardımıyla nasıl belirliyorlar? İlköğretim Online, 8(1), 159-175.

Mariotti, M. A. (2013). Introducing students to geometric theorems: how the teacher can exploit the semiotic potential of a DGS. ZDM Mathematics Education, 45(3), 441-452.

Milli Eğitim Bakanlığı (MEB). (2017). Matematik dersi öğretim programı (ilkokul ve ortaokul 1, 2, 3, 4, 5, 6, 7 ve 8. siniflar). Ankara.

Milli Eğitim Bakanlığı (MEB). (2018). Ortä̈ğretim matematik dersi ögrretim programı. Ankara.

Mitchelmore, M., and White, P. (2007). Abstraction in mathematics learning. Mathematics Education Research Journal, 19(2), 1-9.

Nurhasanah, F., Kusumah, Y. S., Sabandar, J., and Suryadi, D. (2017). Mathematical abstraction: constructing concept of parallel coordinates. In Journal of Physics: Conference Series, 895(1), 1-6.

Pazarbaşı, B., N. (2015). İlköğretim matematik öğretmen adaylarının analitik geometri alan dilini kullanma becerileri ve tutumlarının incelenmesi, Yayımlanmamış Yüksek Lisans Tezi, Gazi Üniversitesi, Ankara.

Pazarbaşı, B., N. ve Es, H. (2015). İlköğretim matematik öğretmen adaylarının analitik geometri alan dilini kullanma becerileri ve tutumlarının incelenmesi, Uluslararası Ĕgitim Bilimleri Dergisi, 2(5), 529-535.

Sezgin Memnun, D. ve Altun, M. (2012). İki altıncı sınıf öğrencisinin doğru denklemini oluşturma sürecinin incelenmesi. Necatibey Eğitim Fakültesi Elektronik Fen ve Matematik Ĕ̈itimi Dergisi (EFMED), 6(1), 171-200.

Toluk Uçar, Z. (2011). Öğretmen adaylarının pedagojik içerik bilgisi: öğretimsel açıklamalar. Türk Bilgisayar ve Matematik Ĕ̈itimi Dergisi, 2(2), 87-102.

Ulaş, T. ve Yenilmez, K. (2017). Sekizinci sınıf öğrencilerinin özdeşlik kavramını oluşturma süreçlerinin incelenmesi. International e-Journal of Educational Studies (IEJES). 1(2), 103-117.

White, P., and Mitchelmore, M. C. (2010). Teaching for abstraction: A model. Mathematical Thinking and Learning, 12(3), 205-226.

Yıldırım, A. ve Şimşek, H. (2008). Sosyal bilimlerde nitel araştırma yöntemleri. 6. Baskı. Ankara: Seçkin Yayıncılık. 


\section{SUMMARY}

The main purpose of analytical geometry is to solve geometry problems by introducing an algebraic explanation to them (Altun, 2014:387). For this reason, it can be said that the analytic geometry and the algebra are intertwined. Although the rotation transformations are found in the curriculum of the 12th grade geometry course, the foundations are laid in the middle school, so the knowledge of the middle school teachers is important. In this study, the process of forming algebraic formulas of rotational transformation in plane of prospective middle school mathematics teachers who have taken and are currently taking analytical geometry courses are investigated. RBC is a cognitive abstraction theory and can be used to examine the process of creating and enhancing mathematical structures from the middle school to the graduate school. It also allows examination of the creation process of geometric concepts. This information was used in light of this study to examine the process of creating the concept of rotation which is a structure related to analytical geometry of undergraduate students. This research is a descriptive study that examines the process of forming transformation formulas of prospective middle school mathematics teachers. Second and third year students who have taken or are taking analytic geometry course have participated to the research. Of the 57 teacher candidates participating in the survey, 33 are third and 24 are second-year students. While the third questions directed to the prospective teachers are managed by drawing to the third grade, the second grades are given as text. The aim here is to see if the prospective teachers are making the drawing themselves and the drawing is ready to make a difference in structuring the transformation formulas. The questions are designed to be analyzed in terms of RBC abstraction theory. The first question is simple, and requires only exhibit the $R$-recognizing behavior. In addition to defining the second question, $B$ building with behavior also needs to be exhibited. Prospective teachers should be able to determine the paired angles in the rotation process and make solutions accordingly. The final question is to construct the transformation formula (C-constructing).

The first question that the recognition of the concept of rotation is enough for the solution was answered correctly by all of the prospective teachers. This was an expected situation. In the second question 45 of them answered correctly whereas in the third question this number decreased to 23. Twenty of the 45 prospective teachers who did the second question correctly seem to have done the third question correctly. A more striking result is that 3 out of 12 prospective teachers who made the second question wrong, which is a simpler level than the third question, make the third question correctly addressing the construction step. When the papers of these prospective teachers are examined qualitatively, it is seen that the two of them who do the third question correctly use the sum-difference formulas and form the desired formula in the second question, instead of rotating the point to the desired angle, they take symmetry with respect to the $x$ axis.

When the papers of are examined within the framework of RBC theory, it is determined that 17 of the 23 prospective teachers who do the third question correctly (Ö1, Ö6, Ö7, Ö8, Ö10, Ö16, Ö17, Ö24, Ö30, Ö31, Ö32, Ö35, Ö39, Ö53, Ö57, Ö59, O65) structured the transformation formulas. It 
has been found that six prospective teacher memorize what points are to be achieved in the resultant formulas or in a certain angle measure $\left(90^{\circ}-180^{\circ}-270^{\circ}-360^{\circ}\right)$.

As a result, it can be said that the prerequisite for construction the rotation transformation formula in the plane is to know and use the concept of rotation theoretically. It can be said that participants who can form the rotation transformation formula can both recognize and build-with the concept of rotation. Despite the difficulty of building-with, only two prospective teachers could be constructed this formula. As mentioned in the findings, the difficulty that prospective teachers experience in building-with is due to confusion of the notion of symmetry with the concept of turning. Another result emerging from the examination of papers is that prospective teachers who are able to explain what they are doing are more successful in constructing the rotation transformation formulas. 